\title{
A Deep Prospective of Complications in Pulmonary Arterial Hypertension Associated with Congenital Heart Disease
}

\section{Heidari $F^{*}$}

Regulation Documentation Scientist, London, UK

*Corresponding author: Farzad Heidari, Regulation Documentation Scientist, The Vestry House, 60 St Giles High Street, WC2H 8LG, London, UK, Tel: +4407474407770; E-mail: farzad720@gmail.com

Received date: November 08, 2017; Accepted date: November 23, 2017; Published date: November 30, 2017

Copyright: () 2017 Heidari F. This is an open-access article distributed under the terms of the Creative Commons Attribution License, which permits unrestricted use, distribution, and reproduction in any medium, provided the original author and source are credited.

\author{
Abstract \\ In high-cholesterol countries such as Western Europe and USA, hypertension, through numerous epidemiological \\ studies, has been established as a definite and, risk factor for the development of coronary heart disease (CHD). \\ This is in contrast to the epidemiological situation in certain Eastern countries.
}

Keywords: Coronary heart disease; Hypertension

\section{Introduction}

In these low cholesterol countries, the prevalence of $\mathrm{CHD}$ is extremely low despite a rather high prevalence of hypertension. It is believed that hypertension needs the metabolic basis of a certain blood lipid level to become an atherogenic factor of clinical importance. In most countries in the Western World, this metabolic basis is endemic and hypertension is recognized as a definite risk factor for CHD. Nevertheless, randomized, controlled hypertension drug trials with placebo-treated or untreated control groups have failed to show a definite preventive effect on CHD. Thus, the Australian trial [1], the best-designed hypertension study, with both placebo-treated controls and adequate numbers, came out with the same MI incidence figures in the drug-treated and the placebo-treated group (33 in each group after 4 years). The test drugs in this study were a thiazide (first step), adding a p-blocker or methyldopa (second step), and hydralazine or clonidine (third step). In the smaller Oslo Study of mild hypertension [2], the control group was untreated. The men in this study, aged 40-49, were followed for 5 years. The 5-year total mortality was the same in both groups, while there were 20 fatal and non-fatal coronary events in the drug-treated group and 13 in the control group (NS). After 10 years, total mortality was still the same in both groups (21 in the treated vs. 20 in the untreated group), while the CHD mortality figures were definitely to the disadvantage of the drug-treated group (14 vs. 3, p<O.OI) [3]. About 95\% of the drug-treated men received a thiazide, alone or in combination with other drugs, mainly propranolol or methyldopa. In the extensive American Multiple Risk Factor Intervention Trial (MRFIT) of 12866 CHD high-risk men, aged 35-57 [4], about 8000 men in the special intervention group (SI) and in the control group (UC) were regarded as hypertensives. In the SI group, these men were treated with a thiazide or chlorthalidone as the first drug. After 7 years both total and CHD mortality were the same in both groups. However, in a subgroup of about 2400 hypertensive men with minor resting ECG abnormalities at the start, a $65 \%$ excess CHD mortality occurred in the SI group (29.2 vs. 17.7 per 1OOO). Using the MRFIT ECG criteria, the same trend with excess CHD incidence in the experimental groups was also found in the Hypertension Detection Follow-up Program and in the Oslo Study.
These results are in sharp contrast to the achievement in 2087 nonhypertensive smokers with a high initial cholesterol level, in whom CHD mortality decreased by $49 \%$ after diet and antismoking advice. This subgroup of MRFIT is similar to the men in the Oslo study dietsmoking trial [5], in which a reduction in CHD incidence of the same order was achieved in the intervention group as compared with the control group.

In 2009 the death rate from CHD in men, aged 35-74, in Denmark, Norway and Sweden was about the same, about 3257 per 1 OOOO0, while Finland topped the world list with almost 4127 [6]. When it comes to changes in CHD death rates, some interesting differences emerge between the Nordic countries. While the CHD death rate is on the decrease during 1969-77 in Finland, and especially in Norway, it is definitely increasing in Sweden and almost unchanged in Denmark (a small increase). The reasons for these differences between the Nordic countries are unknown. However, it can hardly be maintained that they are due to an increased prevalence of untreated hypertension in Sweden as compared with the other countries. The fact that controlled, randomized hypertension drug trials with untreated or placebo-treated control groups have failed to show a preventive effect, and possible adverse effects, on the incidence of $\mathrm{CHD}$, has aroused a suspicion that the adverse metabolic effects of some commonly used antihypertensive drugs might counteract the beneficial effect of pressure lowering. Significant adverse effects of diuretics on serum total cholesterol, HDL cholesterol and triglycerides were observed in the SI group of MRFIT [7]. In the Oslo study of mild hypertension the combination of propranolol and hydrochlorothiazide reduced serum HDL cholesterol [8], increased fasting blood glucose and triglycerides significantly more than hydrochlorothiazide alone [9]. That diuretics increase serum triglycerides and uric acid and impair glucose tolerance is an old experience, as is their potassium-wasting effect with its possible bearing on the induction of fatal arrhythmias in CHD. With regard to B-adrenergic blockers, many studies have shown that both/3-I selective and unselective blockers reduce the favorable HDL cholesterol and increase triglycerides [10-12], with the possible exception of pindolol [13]. On the other hand, the a-blocker prazosin has proved to exert a favorable effect on blood lipids by lowering the atherogenic cholesterol fractions of serum LDL + VLDL and of triglycerides [11]. The clinical importance of the observed metabolic effects of some antihypertensive drugs is still uncertain, and caution should be exercised when it comes 
Citation: Heidari F (2017) A Deep Prospective of Complications in Pulmonary Arterial Hypertension Associated with Congenital Heart Disease.

Page 2 of 2

to their practical implications. However, the fact that $\mathrm{CHD}$ has not been shown to be preventable by drug treatment of hypertension should lead to serious considerations of both the pressure lowering and the metabolic effects of antihypertensive drugs. This might be of special importance for the long-term treatment of mild hypertension in young people. New long-term hypertension studies, adequately designed and controlled, are needed. In mild hypertension, the place of the non-pharmacologic approach should be established. In more pronounced hypertension, drugs devoid of overt adverse metabolic effects, or rather with a favorable metabolic profile, should be tested. Such new studies might solve the hypertension-CHD dilemma.

\section{References}

1. Management Committee on the Australian therapeutic trial in mild hypertension (1982) Lancet.

2. Helgeland A (1980) Treatment of mild hypertension: a five-year controlled drug trial: The Oslo Study. Am J Med 69: 725-732.

3. Helgeland A, Hjermann I, Holme I, Lund LPG, Leren P (1984) Letter to the Editor. JAMA.

4. Multiple Risk Factor Intervention Trial Research Group (1982) Risk factor changes and mortality results. JAMA 248: 1465-1477.

5. Hjermann I, Byre KV, Holme J, Leren P (1981) Effect of diet and smoking intervention on the incidence of coronary heart disease: report from the
Oslo Study Group of a randomised trial in healthy men. Lancet 2: 1303-1310.

6. Stamler J, Stamler R (2011) Intervention for the prevention and control of hypertension and atherosclerotic diseases: United States and international experience. Am J Med 76: 13-26.

7. Lasser NL, Grandite G, Caggiula AW (1984) Effects of antihypertensive therapy on plasma lipids in the Multiple Risk Factor Intervention Trial. Am J Med 76: 52-66.

8. Helgeland A, Hjermann I, Leren P, Enger SC, Holme I (1978) High density lipoprotein cholesterol and antihypertensive drugs. Br Med J 2: p403.

9. Helgeland A, Leren P, Foss OP (1984) Serum glucose levels during longterm observation of treated and untreated men with mild hypertension. Am J Med 76: 802-805.

10. Day JL, Metcalfe J, Simpson N, Lowenthal L (1984) Adrenergic mechanisms in the control of plasma lipids in man. Am J Med 76: 94-96.

11. Leren P, Foss OP, Helgeland A, Hjermann I, Holme, et al. (1982) Effect of propranolol and prazosin on blood lipids. Lancet 2: 4-6.

12. Kjeldsen SE, Eide J, Leren P, Foss OP, Holme J, et al. (1982) The effect on HDL cholesterol of oxprenolol and atenolol. Scand J Clin Lab Invest 42: 449-453.

13. Leren P, Foss OP, Helgeland A, Hjermann I, Holme J (1981) Effect of pindolol and hydrochlorothiazide on blood lipids. Clin Trial J 18: 254-261. 